\title{
REVERSIBILIDADE DE FÓSFORO NÃO-LÁBIL EM SOLOS SUBMETIDOS À REDUÇÃO MICROBIANA E QUÍMICA. II - EXTRAÇÕES SUCESSIVAS DO FÓSFORO PELA RESINA DE TROCA ANIÔNICA ${ }^{(1)}$
}

\author{
Iván Ernesto Fernández R. ${ }^{(2)}$, Roberto Ferreira Novais ${ }^{(3)}$, Flancer \\ Novais Nunes $^{(4)}$ \& João Carlos Ker ${ }^{(3)}$
}

\begin{abstract}
RESUMO
A formação de P não-lábil a partir de formas lábeis, adsorvidas aos oxihidróxidos de $\mathrm{Fe}$ e Al, é razão para o baixo efeito residual da fertilização fosfatada em solos tropicais. A reversibilidade do $P$ não-lábil para formas lábeis nesses solos pode ser favorecida pela redução do $\mathrm{Fe}^{3+} \mathrm{e}$, ou, pela diminuição da atividade dos oxihidróxidos de Fe e Al. Neste trabalho, objetivou-se avaliar a adsorção e dessorção de P, sua transformação em não-lábil e reversibilidade dessa forma em amostras de solos submetidas à redução microbiana ou química. Para isso, amostras de 11 solos foram homogeneizadas com $300 \mathrm{mg} \mathrm{kg}^{-1}$ de $\mathrm{P}$ na forma de $\mathrm{NaH}_{2} \mathrm{PO}_{4} \mathrm{em}$ solução, incubadas por 30 dias e, então, submetidas a dez extrações sucessivas de $\mathrm{P}$ com resina de troca aniônica (RTA) (tratamento sem redução). Em seguida, outras amostras dos solos foram submetidas à ambiente redutor em solução de sacarose $0,1 \mathrm{~mol} \mathrm{~L}^{-1} \mathrm{com}$ posterior aplicação da doses de $P\left(300 \mathrm{mg} \mathrm{kg}^{-1}\right)$ e as dez extrações sucessivas de $P$ (tratamento redução microbiana). Depois, outras amostras foram reduzidas/ complexadas com oxalato de amônio (Ox) ou com citrato-ditionito-bicarbonato (CDB), e os solos/resíduos receberam a mesma dose de $\mathrm{P}$ dos experimentos anteriores. Foram então incubados por 30 dias e submetidos às extrações sucessivas com RTA (tratamento redução química). A capacidade máxima de adsorção de $\mathbf{P}$ (CMAP) dos solos mostrou-se mais dependente da goethita (com 70,8 \% de contribuição para seu valor) do que da gibbsita (com contribuição de $29,2 \%$ ). A correlação negativa entre os teores de P obtidos na segunda extração com a RTA, nos solos em condição natural, sem redução, e os teores de gibbsita sugere que este,
\end{abstract}

\footnotetext{
(1) Recebido para publicação em junho de 2008 e aprovado em outubro de 2008.

(2) Professor Associado, Faculdad de Ciencias, Universidade de La Serena. Benavente 980, La Serena, Chile. E-mail: ifernandezrojas@hotmail.com

${ }^{(3)}$ Professor do Departamento de Solos, Universidade Federal de Viçosa - UFV. E-mail: rfnovais@ufv.br; jcker@ufv.br

(4) Doutorando em Solos e Nutrição de Plantas pelo Departamento de Solos, UFV. E-mail: flancernovais@yahoo.com.br
} 
e não a goethita, é o oxihidróxido responsável pela maior restrição à dessorção do $P$. Os valores de CMAP, estimados por meio do $P$ remanescente (P-rem), mostraram, nas amostras submetidas ao tratamento com redução microbiana, pequena alteração para o grupo dos solos menos oxídicos, com menor CMAP. Todavia, nos solos mais oxídicos, com maior CMAP, o efeito prévio da sacarose foi o aumenta do P-rem (diminuição da CMAP) 10 vezes em relação aos solos para o tratamento sem redução. Entretanto, a redução gerada pela sacarose não alterou a dessorção do $\mathbf{P}$ anteriormente adsorvido. A expectativa de que ocorreria significativa reversibilidade de $\mathbf{P}$ não-lábil com a redução microbiana ou química dos solos não se concretizou, demonstrando a grande estabilidade dessas formas.

Termos de indexação: potencial redox, dessorção de P, gibbsita, goethita, oxalato, CDB, $P$ residual.

\title{
SUMMARY: REVERSIBILITY OF NON-LABILE PHOSPHORUS IN SOILS UNDER MICROBIAL AND CHEMICAL REDUCTION. II - SUCCESSIVE ANION EXCHANGE RESIN EXTRACTION OF PHOSPHORUS
}

\begin{abstract}
The formation of non-labile from labile $P$ forms, adsorbed onto $\mathrm{Fe}$ and Al oxyhydroxides, is the reason for low residual of phosphate fertilization in tropical soils. The reversibility of non-labile $P$ to labile forms in these soils may be favored by the reduction of $\mathrm{Fe}^{3+}$ and, or, by the reduced activity of $\mathrm{Fe}$ and $\mathrm{Al}$ oxyhydroxides. This study aimed to evaluate $P$ adsorption and desorption, the transformation into non-labile forms and reversibility of these forms in soil samples from environments of microbial or chemical reduction. Samples of 11 soils were homogenized with $300 \mathrm{mg} \mathrm{kg}^{-1} \mathrm{P}\left(\mathrm{NaH}_{2} \mathrm{PO}_{4}\right)$ in solution and incubated for 30 days. $P$ was extracted in 10 successive extractions with anion-exchange resin (AER) (treatment without reduction). In a second experiment, the soil samples were treated with $0.1 \mathrm{~mol} \mathrm{~L}^{-1}$ sucrose solution to create a reduction enrviroment and subsequent application of $P$ dose (300 mg kg-1) and 10 successive $P$ extractions (treatment microbial reduction). In a third experiment, the samples were complexed/reduced with ammonium oxalate $(\mathrm{Ox})$ or with citrate-dithionite-bicarbonate $(C D B)$. The soils/residues were treated with the above $P$ dose, incubated for 30 days and subjected to successive extractions with AER (chemical reduction). It was observed that maximum $P$ adsorption capacity (MPAC) of the soils was closer related with goethite, (which accounted for $70.8 \%$ of the value), than gibbsite (with a contribution of $29.2 \%$ ). The negative correlation between the $P$ contents in the second AER extraction for the soils in natural condition without reduction, and the contents of gibbsite only, indicated that gibbsite and not goethite is the oxyhydroxide that restricts $P$ desorption most. The MPAC values estimated by equilibrium $P$ showed, in the samples treated with microbial reduction, a slight alteration for the group of the less oxidic soils, with lower MPAC. But for more oxidic soils with higher MPAC, the previous effect of sucrose, which increased equilibrium $P$ (reducing the MPAC), was high, about 10 times higher than in soils of the treatment without reduction. However, the reduction caused by sucrose did not alter the desorption of previously adsorbed $P$. The expectation of a significant reversibility of non-labile $P$ due to microbial or chemical reduction of the soils was not confirmed, demonstrating the great stability of this form.
\end{abstract}

Index terms: Redox potential, $P$-desorption, gibssite, goethite, oxalate, $C D B$, residual $P$.

\section{INTRODUÇÃO}

A retenção de $\mathrm{P}$ em formas não-reversíveis ou pouco reversíveis, denominadas não-lábeis, significa, de modo particular para solos mais intemperizados e mais oxídicos, forte competição entre solo e planta pelo $\mathrm{P}$ aplicado na forma de fertilizante.
O termo utilizado para descrever os processos de retenção de $\mathrm{P}$ no solo apresenta controvérsia, dada a complexidade dos fenômenos envolvidos. $\mathrm{Na}$ literatura, observam-se diversos termos, como fixação para designar a adsorção não reversível de $\mathrm{P}$ no solo (Novais et al., 2007; Srinivasarao et al., 2007). Nas reações de adsorção, podem-se distinguir duas fases: 
uma mais rápida nos sítios ativos de superfície, via atração eletrostática, seguida de outra mais lenta, quando ocorre troca de ligantes dos grupamentos $\mathrm{OH}^{-}$ e $\mathrm{OH}_{2}{ }^{+}$pelos íons ortofosfatos (Parfitt, 1978). A ligação pode apresentar menor energia, caracterizada pela formação de complexos monodentados, ou maior caracterizada pelos complexos bidentados que resultam na formação de P não-lábil (Parfitt, 1989; Novais et al., 2007). Portanto, a fixação que dá origem ao $\mathrm{P}$ não-lábil compreende fenômenos que se iniciam pela adsorção-precipitação reversível do íon ortofosfato da solução do solo até sua irreversibilidade. Também caracterizada pela difusão do fosfato nas imperfeições de cristais, esse fenômeno denominada de difusão em fase sólida (Barrow, 1985), esse fenômeno torna o P menos disponível ou não-lábil (Parfitt, 1989).

Tentativas para relacionar a retenção de $\mathrm{P}$ com a mineralogia do solo têm mostrado que os oxihidróxidos de Fe e de $\mathrm{Al}$ participam ativamente deste fenômeno (Novais et al., 2007). A magnitude da retenção de $\mathrm{P}$ em solos tropicais, em resposta à sua mineralogia, considera a presença de matéria orgânica (Almeida et al., 2003), tipo de argila e grau de cristalização dos oxihidróxidos de $\mathrm{Fe}$ e Al. Os amorfos apresentam maior capacidade de retenção ou adsorção de $\mathrm{P}$ (Novais \& Smyth, 1999).

Para Latossolos, a goethita é o principal componente da fração argila responsável pela adsorção de P (Bahia Filho et al., 1983; Novais \& Smyth, 1999). A substituição isomórfica do $\mathrm{Fe}$ por $\mathrm{Al}$ em goethita provoca desarranjo estrutural pela redução do tamanho da célula unitária, contribuindo com maior superfície específica e, consequentemente, com maior adsorção de P (Agbenin, 2003; Rolim Neto et al., 2004).

A presença de oxihidróxidos de Fe nos solos e sua estabilidade é influenciada por condições físicoquímicas que favorecem a redução de compostos férricos. Solos sujeitos a alagamento, principalmente quando há maior disponibilidade de $\mathrm{C}$ como fonte de energia para a microbiota, apresentam maior redução do $\mathrm{Fe}^{3+}$, devido à diminuição do potencial redox (Eh), e, como conseqüência, apresentam maior teor de $\mathrm{P}$ disponível para as plantas (Scalengue et al., 2002; Chacon et al., 2006). Os mecanismos propostos para esse fenômeno envolvem a hidrólise dos fosfatos de $\mathrm{Fe}$ e de $\mathrm{Al}$, a redução das formas férricas a ferrosas e a dissolução de ortofosfatos como conseqüência da diminuição do Eh, o que propicia a liberação de $\mathrm{P}$ tanto adsorvido quanto ocluso nos oxihidróxidos (Hutchison \& Hesterberg, 2004; Chacon et al., 2006).

Estudos sobre a cinética de transformação de Plábil em não-lábil em solos de Cerrado demonstraram aumento inicial do teor de $\mathrm{P}$ ligado a $\mathrm{Al}$ em relação ao ligado a Fe. Essa situação foi revertida, entretanto, com o aumento do tempo de incubação do $\mathrm{P}$, dada a maior estabilidade da ligação P-Fe (Gonçalves et al., 1989). A reversibilidade do $P$ não-lábil a lábil, recuperado pela resina de troca aniônica, é muito pequena, não havendo correlação significativa com características do solo (Campello et al., 1994). Por outro lado, a passagem de P-lábil para não-lábil é bastante rápida, atingindo aproximadamente de $50 \%$ da dose de P aplicada em 15 dias de contato com solos argilosos (Gonçalves et al., 1989; Campello et al., 1994).

O objetivo deste trabalho foi avaliar a capacidade de adsorção e de dessorção de $\mathrm{P}$ em amostras de solos submetidas à redução microbiana ou química, com ênfase à formação e reversibilidade do $\mathrm{P}$ não-lábil e sua dependência de constituintes químicos e mineralógicos do solo.

\section{MATERIAL E MÉTODOS}

\section{Solos utilizados}

Amostras da camada de 0 a $20 \mathrm{~cm}$ de profundidade de 11 solos foram coletadas em áreas com vegetação natural nos municípios de Campina Verde, Sete Lagoas, Paracatu, Patrocínio, Três Marias e Uberaba, no Estado de Minas Gerais, e nos municípios de Aracruz e Açailândia nos Estados do Espírito Santo e do Maranhão. Os solos compreendem ampla variação textural e pertencem às classes: Neossolo Quartzarênico (RQ), Latossolo Amarelo (LA), Latossolo Vermelho (LV) e Latossolo Vermelho-Amarelo (LVA). As amostras dos solos foram secas ao ar e passadas em peneira com $2 \mathrm{~mm}$ de abertura e submetidas à caracterização química, física e mineralógica (Quadro 1).

Para a caracterização mineralógica dos solos foram obtidos os difratogramas de raios-X da fração argila e, para a quantificação de seus constituintes, utilizouse o método da alocação (Resende et al., 1987). Também foram determinados os teores totais de Fe, $\mathrm{Al}$ e $\mathrm{P}$ após ataque nítrico-perclórico $\left(\mathrm{HNO}_{3}: \mathrm{HClO}_{4}\right.$ (8:3, v/v)) nessas amostras. As amostras foram, também, submetidas ao ataque sulfúrico, determinando-se os teores de $\mathrm{SiO}_{2}, \mathrm{Al}_{2} \mathrm{O}_{3}, \mathrm{Fe}_{2} \mathrm{O}_{3}, \mathrm{TiO}_{2}$ e $\mathrm{P}_{2} \mathrm{O}_{5}$, segundo Embrapa (1997).

\section{Incubação das amostras de solo com fósforo e extrações sucessivas com resina de troca aniônica com posterior redução microbiana na presença de sacarose (Tratamento sem redução)}

Amostras de $30 \mathrm{~g}$ dos solos receberam dose de $300 \mathrm{mg} \mathrm{dm}^{-3}$ de $\mathrm{P}$ na forma de $\mathrm{NaH}_{2} \mathrm{PO}_{4}$ em solução. Após a homogeneização desta fonte de $\mathrm{P}$ com o solo, a umidade foi elevada a $80 \%$ da capacidade de campo e as amostras foram incubadas em sacolas plásticas por 30 dias. Terminado esse período, as amostras foram secas ao ar e submetidas a dez extrações sucessivas com resina de troca aniônica (RTA) (Amberlite IRA 400), acondicionada em saquinhos de poliéster, conforme Raij \& Quaggio (1983). Depois disso, as amostras residuais dos solos foram submetidas à 
Quadro 1. Características químicas, físicas e mineralógicas das amostras dos solos; Neossolo Quartzarênico órtico e Latossolo Vermelho distrófico de Campina Verde (CV-RQo e CV-LVd), Latossolo Vermelho ácrico e Latossolo Vermelho distrófico de Três Marias (TM-LVw e TM-LVd), Latossolo Amarelo distrocoeso de Aracruz (ARA-LAdx), Latossolo Amarelo distrófico de Açailândia (AÇA-LAd), Latossolo Vermelho-Amarelo distrófico 1 e 2 de Uberaba (UBE-LVAd1 e UBE-LVAd2), Latossolo Vermelho distrófico de Paracatu, de Sete Lagoas e de Patrocínio (PAR-LVd, SL-LVd e PAT-LVd)

\begin{tabular}{|c|c|c|c|c|c|c|c|c|c|c|c|}
\hline \multirow{2}{*}{ Característica } & \multicolumn{11}{|c|}{ Solo } \\
\hline & CV-RQ & CV-LVd & TM-LVw & TM-LVd & ARA-LAdx & AÇA-LAd & UBE-LVAd1 & UBE-LVAd2 & PAR-LVd & SL-LVd & PAT-LVd \\
\hline $\mathrm{pH} \mathrm{H} \mathrm{H}_{2} \mathrm{O}^{(1)}$ & 5,05 & 4,97 & 4,64 & 4,99 & 4,40 & 5,03 & 5,34 & 5,0 & 4,70 & 4,38 & 4,64 \\
\hline $\mathrm{P}$ total $\left(\mathrm{mg} \mathrm{dm}^{-3}\right)^{(1)}$ & 64 & 243 & 116 & 41 & 64 & 94 & 298 & 363 & 228 & 934 & 439 \\
\hline P Mehlich-1 $\left(\mathrm{mg} \mathrm{dm}^{-3}\right)^{(1)}$ & 2,9 & 1,3 & 0,7 & 0,2 & 0,3 & 1,0 & 0,2 & 0,2 & 0,5 & 1,3 & 0,2 \\
\hline P resina $\left(\mathrm{mg} \mathrm{dm}^{-3}\right)^{(2)}$ & 1,2 & 1,5 & 1,5 & 1,2 & 0,8 & 0,8 & 3,1 & 3,1 & 1,4 & 0,5 & 0,8 \\
\hline $\mathrm{P}$ remanescente $\left(\mathrm{mg} \mathrm{L}^{-1}\right)^{(3)}$ & 37,1 & 21,1 & 38,1 & 29,9 & 29,9 & 46,1 & 3,4 & 4,8 & 4,6 & 3,2 & 1,8 \\
\hline $\mathrm{CMAP}\left(\mathrm{mg} \mathrm{g}^{-1}\right)^{(4)}$ & 0,397 & 0,659 & 0,335 & 0,434 & 0,453 & 0,299 & 1,673 & 1,887 & 1,728 & 1,757 & 1,936 \\
\hline $\mathrm{SiO}_{2}\left(\mathrm{~g} \mathrm{~kg}^{-1}\right)^{(5)}$ & 46,2 & 77,2 & 45,8 & 38,4 & 138,6 & 112,8 & 16,48 & 8,82 & 23,58 & 24,76 & 6,70 \\
\hline $\mathrm{Al}_{2} \mathrm{O}_{3}\left(\mathrm{~g} \mathrm{~kg}^{-1}\right)^{(5)}$ & 35,7 & 66,3 & 51,0 & 81,6 & 128,6 & 86,7 & 32,75 & 36,32 & 36,07 & 27,78 & 25,70 \\
\hline $\mathrm{Fe}_{2} \mathrm{O}_{3}\left(\mathrm{~g} \mathrm{~kg}^{-1}\right)^{(5)}$ & 26,9 & 68,9 & 23,0 & 25,0 & 29,9 & 24,0 & 8,79 & 5,88 & 8,18 & 11,68 & 14,12 \\
\hline $\mathrm{TiO}_{2}\left(\mathrm{~g} \mathrm{~kg}^{-1}\right)^{(5)}$ & 5,4 & 23,0 & 8,8 & 9,9 & 19,3 & 8,2 & 1,88 & 2,25 & 1,23 & 1,03 & 0,78 \\
\hline $\mathrm{P}_{2} \mathrm{O}_{5}\left(\mathrm{~g} \mathrm{~kg}^{-1}\right)^{(5)}$ & 0,2 & 0,6 & 0,1 & 0,1 & 0,1 & 0,1 & 0,08 & 0,07 & 0,06 & 0,21 & 0,09 \\
\hline $\mathrm{Al}^{3+}\left(\mathrm{cmol}_{\mathrm{c}} \mathrm{dm}^{-3}\right)^{(1)}$ & 1,13 & 1,41 & 0,75 & 0,75 & 1,50 & 1,29 & 0,90 & 1,08 & 0,89 & 1,74 & 0,52 \\
\hline $\mathrm{Ca}^{2+}\left(\mathrm{cmol}_{\mathrm{c}} \mathrm{dm}^{-3}\right)^{(1)}$ & 0,18 & 0,24 & 0,00 & 0,00 & 0,19 & 1,09 & 0,08 & 0,0 & 0,10 & 0,94 & 0,19 \\
\hline $\mathrm{Mg}^{2+}\left(\mathrm{cmol}_{\mathrm{c}} \mathrm{dm}^{-3}\right)^{(1)}$ & 0,17 & 0,42 & 0,04 & 0,03 & 0,10 & 0,23 & 0,09 & 0,06 & 0,13 & 0,15 & 0,16 \\
\hline $\mathrm{H}+\mathrm{Al}\left(\mathrm{cmol}_{\mathrm{c}} \mathrm{dm}^{-3}\right)^{(1)}$ & 4,64 & 5,22 & 3,17 & 2,48 & 3,64 & 2,94 & 7,89 & 8,28 & 7,89 & 12,84 & 8,66 \\
\hline $\mathrm{SB}\left(\mathrm{cmol}_{\mathrm{c}} \mathrm{dm}^{-3}\right)$ & 0,48 & 0,78 & 0,09 & 0,06 & 0,32 & 1,35 & 0,2 & 0,14 & 0,24 & 1,17 & 0,54 \\
\hline CTC efet. $\left(\mathrm{cmol}_{\mathrm{c}} \mathrm{dm}^{-3}\right)$ & 1,61 & 2,19 & 0,84 & 0,81 & 1,82 & 2,64 & 1,15 & 1,22 & 1,13 & 2,91 & 1,06 \\
\hline CTC total $\left(\mathrm{cmol}_{\mathrm{c}} \mathrm{dm}^{-3}\right)$ & 6,25 & 7,41 & 4,01 & 3,29 & 5,46 & 5,58 & 9,04 & 9,50 & 9,02 & 15,75 & 9,72 \\
\hline $\mathrm{CO}\left(\mathrm{g} \mathrm{kg}^{-1}\right)^{(1)}$ & 5,1 & 8,2 & 5,3 & 3,0 & 2,5 & 7,0 & 2,28 & 2,13 & 2,11 & 2,13 & 2,85 \\
\hline Areia grossa $\left(\mathrm{g} \mathrm{kg}^{-1}\right)^{(6)}$ & 58,0 & 52,0 & 50,0 & 51,0 & 46,0 & 50,0 & 11,0 & 15,0 & 3,0 & 8,0 & 18,0 \\
\hline Areia fina $\left(\mathrm{g} \mathrm{kg}^{-1}\right)^{(6)}$ & 29,0 & 23,0 & 36,0 & 30,0 & 17,0 & 19,0 & 6,0 & 6,0 & 8,0 & 7,0 & 4,0 \\
\hline Silte $\left(\mathrm{g} \mathrm{kg}^{-1}\right)^{(6)}$ & 1,0 & 2,0 & 2,0 & 3,0 & 2,0 & 10,0 & 16,0 & 19,0 & 21,0 & 13,0 & 24,0 \\
\hline Argila $\left(\mathrm{g} \mathrm{kg}^{-1}\right)^{(6)}$ & 12,0 & 23,0 & 12,0 & 16,0 & 35,0 & 21,0 & 67,0 & 60,0 & 68,0 & 72,0 & 54,0 \\
\hline Caulinita $\left(\mathrm{g} \mathrm{kg}^{-1}\right)^{(7)}$ & 86 & 165 & 98 & 83 & 298 & 243 & 354 & 190 & 507 & 143 & 144 \\
\hline Gibsita $\left(\mathrm{g} \mathrm{kg}^{-1}\right)^{(7)}$ & - & - & 16 & 73 & 14 & - & 284 & 438 & 243 & 101 & 304 \\
\hline Goetita $\left(\mathrm{g} \mathrm{kg}^{-1}\right)^{(7)}$ & 37 & 67 & 28 & 29 & 22 & 30 & 96 & 55 & 97 & 143 & 177 \\
\hline $\mathrm{Ki}$ & 2,20 & 1,97 & 1,52 & 0,80 & 1,83 & 2,21 & 0,85 & 0,41 & 1,11 & 1,15 & 0,44 \\
\hline $\mathrm{Kr}$ & 1,15 & 1,18 & 1,18 & 0,67 & 1,60 & 1,88 & 0,73 & 0,37 & 0,97 & 1,19 & 0,33 \\
\hline $\mathrm{AlO}_{3} / \mathrm{Fe}_{2} \mathrm{O}_{3}$ & 2,08 & 1,51 & 3,47 & 5,11 & 6,94 & 5,65 & 5,83 & 9,66 & 6,90 & 3,72 & 2,85 \\
\hline $\mathrm{SiO}_{3} / \mathrm{Fe}_{2} \mathrm{O}_{3}$ & 4,56 & 2,90 & 5,29 & 4,08 & 12,69 & 12,48 & 4,98 & 3,98 & 7,66 & 5,63 & 1,26 \\
\hline
\end{tabular}

(1) Defelipo \& Ribeiro (1997). ${ }^{(2)}$ Raij \& Quaggio (1983). ${ }^{(3)}$ Alvarez V. et al. (2000). ${ }^{(4)}$ Olsen \& Watanabe (1957). ${ }^{(5)}$ Embrapa (1997).

${ }^{(6)}$ Ruiz (2005). ${ }^{(7)}$ Resende et al. (1987).

redução microbiana pela inundação como solução de sacarose $0,1 \mathrm{~mol} \mathrm{~L}^{-1}$, mantendo-se uma lâmina de $3 \mathrm{~cm}$ sobre a superfície do solo. A solução de sacarose foi trocada a cada 15 dias ao longo de 60 dias de tempo total de equilíbrio, determinando-se os valores de Eh e $\mathrm{pH}$, e os teores de $\mathrm{Fe}, \mathrm{Al}$ e $\mathrm{P}$ na solução de sacarose aos 15, 30, 45 e 60 dias.

Redução microbiana das amostras de solo com posterior incubação com fósforo e extração com resina de troca aniônica (Tratamento redução microbiana)

O tratamento denominado "redução microbiana" é semelhante ao anterior (tratamento sem redução). A diferença deste ensaio em relação ao anterior consistiu da incubação das amostras dos solos com sacarose por 60 dias antes da incubação com a dose de $300 \mathrm{mg} \mathrm{dm}^{-3}$ de $\mathrm{P}$, por 30 dias, com umidade elevada à capacidade do campo. Em seguida foram feitas dez extrações sucessivas de $\mathrm{P}$ com RTA, como já descrito.
Redução/complexação das amostras de solo com oxalato de amônio ou com citrato-ditionito-bicarbonato de sódio, com posterior incubação com $\mathrm{P}$ e extração com resina de troca aniônica (Tratamento redução química)

As amostras dos solos também foram submetidas à redução/complexação por quatro extrações sucessivas com oxalato de amônio $(\mathrm{Ox})$ ou duas com citrato-ditionito-bicarbonato de sódio (CDB). Em cada um dos extratos, foram determinados os valores de Eh, pH, e os teores de Fe, Al e P. Depois dessas extrações, as amostras foram incubadas com $300 \mathrm{mg} \mathrm{kg}^{-1}$ de $\mathrm{P}$ por 30 dias conforme descrito anteriormente. Depois disso, as amostras foram submetidas a dez extrações sucessivas de P com RTA.

\section{Determinação do fósforo remanescente}

Nas amostras dos solos antes e após os tratamentos com sacarose, $\mathrm{Ox}$ e $\mathrm{CBD}$, foi determinado o $\mathrm{P}$ remanescente (P-rem) na solução de equilíbrio após a 
agitação de $2,5 \mathrm{~g}$ de solo em $25 \mathrm{~mL}$ de solução contendo $60 \mathrm{mg} \mathrm{L}^{-1}$ de $\mathrm{P}$ em $0,01 \mathrm{~mol} \mathrm{~L}^{-1}$ de $\mathrm{CaCl}_{2}$, conforme Alvarez V. et al., (2000). O teor de P na solução de equilíbrio foi determinado por espectrofotometria de absorção molecular do complexo fosfomolibídico, conforme Murphy \& Riley (1962).

\section{Análise dos dados}

Para relacionar o efeito do número de extrações sucessivas pela resina sobre o $\mathrm{P}$ dessorvido utilizouse o modelo $\mathrm{CE}=\mathrm{Co}(\mathrm{K} \mathrm{E} / \mathrm{b})^{-\mathrm{b}}$ (Barrow, 1974) com adaptação sugerida por Gonçalves et al. (1989), em que $\mathrm{CE}$ é o $\mathrm{P}$ recuperado (dessorvido) pela RTA em $\mathrm{mg} \mathrm{kg}{ }^{-1}$, Co é o $\mathrm{P}$ aplicado $\left(300 \mathrm{mg} \mathrm{kg}^{-1}\right)$, K é a taxa de dessorção de $\mathrm{P}$, E é o numero de extrações sucessivas, e b é uma constante. Foi adotado o delineamento de blocos casualizados com três repetições num fatorial $11 \times 4$, com 11 solos e quatro tratamentos de redução. Também, foram calculadas correlações lineares simples entre as características químicas, físicas e mineralógicas, e os resultados obtidos em solos sem e com redução.

\section{RESULTADOS E DISCUSSÃO}

$\mathrm{Na}$ avaliação do $\mathrm{P}$ recuperado por meio das extrações sucessivas pela resina de troca aniônica (RTA), observou-se que os teores de $\mathrm{P}$ nas amostras dos solos, independente do tratamento de redução microbiana com sacarose, com oxalato de amônio (Ox), ou redução com citrato-ditionito-bicarbonato de sódio (CDB), permitem separá-los, de modo geral, em dois grupos de solos: os mais e os menos oxídicos (Quadros 1 e 2). Mesmo que, após a redução com $\mathrm{CDB}$, o teor de $\mathrm{P}$ total obtido pelo somatório das extrações sucessivas com RTA (PrT) seja superior ao extraído nas demais condições, a variabilidade dos valores segue o mesmo padrão nos três procedimentos de redução quanto a esse agrupamento de solos. Observa-se que, consistentemente, os menores valores de PrT são encontrados nos solos mais ricos em gibbsita e goethita, Latossolo Vermelho-Amarelo distrófico 1 e 2 de Uberaba (UBE-LVAd1 e UBE-LVAd2), Latossolo Vermelho distrófico de Paracatu, de Sete Lagoas e de Patrocínio (PAR-LVd, SL-LVd e PAT-LVd, respectivamente), enquanto os maiores são encontrados naqueles mais cauliníticos: Neossolo Quartzarênico órtico e Latossolo Vermelho distrófico de Campina Verde (CV-RQo e CV-LVd), Latossolo Vermelho ácrico e Latossolo Vermelho distrófico de Três Marias (TM-LVw e TM-LVd), Latossolo Amarelo distrocoeso de Aracruz (ARA-LVdx) e Latossolo Amarelo distrófico de Açailândia (AÇA-LAd) (Quadros 1 e 2).

Para todas as condições de redução utilizadas, sem redução $(\operatorname{PrN})$, redução microbiana com sacarose $(\mathrm{PrS})$ e redução química com $\mathrm{Ox}(\mathrm{PrOx})$ e $\mathrm{CDBm}$
(PrCDB), o PrT correlacionou-se negativa e significativamente com gibbsita e com goethita (Quadro 3). Essa correlação indica o envolvimento desses dois oxihidróxidos na adsorção de $\mathrm{P}$ nos solos, como também observado em outros trabalhos (Parfitt, 1978; Barrow, 1985; Yuan \& Lavkulich, 1994; Souza et al., 2006). Como o PrT reflete o P-lábil desses solos, dado o método de extração utilizado (resina), verificase que o $\mathrm{P}$ não-extraído, o teor de $\mathrm{P}$ não-lábil formado a partir da dose aplicada (300 $\mathrm{mg} \mathrm{kg}^{-1}$ de P), é positivamente dependente tanto da goethita como da gibbsita.

$\mathrm{Na}$ avaliação dos teores de $\mathrm{P}$ obtidos pelas extrações sucessivas com resina, em todos os tratamentos (Quadro 2), observou-se que os teores obtidos na primeira extração com resina ( $\operatorname{Pr} 1)$ correlacionaramse negativamente com os teores de gibbsita e de goethita (Quadro 3). Todavia, os teores de P na segunda extração para as amostras dos solos no tratamento sem redução (Pr2N) foram significativos apenas com gibbsita. Esse efeito da gibbsita restringindo a segunda extração pela resina no tratamento sem redução ocorreu, de maneira particular, nos solos UBE-LVAd1, UBE-LVAd2 e PAT-LVd deste grupo, com os maiores teores de gibbsita (Quadro 1). A menor presença de gibbsita no SL-LVd, embora com o segundo maior teor de goethita, fez com que a segunda extração no tratamento sem redução fosse bastante elevada, semelhante à do solo TM-LVd. Este solo na primeira extração liberou 101,01, contra apenas $61,16 \mathrm{mg} \mathrm{kg}^{-1}$ de P no solo SL-LVd (Quadro 2). Esses resultados sugerem que a segunda extração que, provavelmente, indicaria uma forma de $\mathrm{P}$ ligada ao solo com mais energia, teria na gibbsita, e não na goethita, o oxihidróxido responsável pela maior restrição à dessorção do $\mathrm{P}$.

Comportamento bastante distinto dos demais solos apresenta o PAT-LVd no tratamento sem redução, quanto à extração de $\mathrm{P}$ pela resina (Quadro 2). Esse solo apresentou o menor valor de $\operatorname{PrT}\left(80,46 \mathrm{mg} \mathrm{kg}^{-1}\right)$, representando apenas $26,82 \%$ do $\mathrm{P}$ adicionado (300 mg kg-1). Os altos teores de gibbsita e de goethita, aliados ao baixo teor de caulinita (Quadro 1), esta como amenizadora do poder de adsorção de $\mathrm{P}$ destes oxihidróxidos, seriam os responsáveis pelo menor PrT. Isso, devido ao capeamento da caulinita por esses oxihidróxidos diminuir os sítios de adsorção dos minerais de ambos os grupos (Kafkafi et al., 1967; McLaughlin et al., 1981). No entanto, com teores também altos de gibbsita e de goethita (Quadro 1), o solo UBE-LVAd2 apresentou maior dessorção do que o PAT-LVd (Quadro 2), possivelmente por causa de seu maior teor de caulinita. Situação semelhante ocorre com o UBE-LVAd1. Esse solo, PAT-LVd, apresentou maior dessorção de $\mathrm{P}$ na primeira extração (Pr1) no tratamento sem redução, comparativamente aos tratamentos em que a redução/solubilização de formas amorfas de $\mathrm{Fe}$ foi menos drástica (microbiana e Ox) (Quadro 2). Essa observação sugere que a Pr1 está mais dependente da gibbsita e que a extração de 
Quadro 2. Teor de P nas dez extrações sucessivas com resina de troca aniônica (Pr), somatório dos teores das dez extrações sucessivas (PrT) e valores relativos de $P$ recuperado $(R)$ em relação ao aplicado em amostras dos solos; Neossolo Quartzarênico órtico e Latossolo Vermelho distrófico de Campina Verde (CV-RQo e CV-LVd), Latossolo Vermelho ácrico e Latossolo Vermelho distrófico de Três Marias (TMLVw e TM-LVd), Latossolo Amarelo distrocoeso de Aracruz (ARA-LAdx), Latossolo Amarelo distrófico de Açailândia (AÇA-LAd), Latossolo Vermelho-Amarelo distrófico 1 e 2 de Uberaba (UBE-LVAd1 e UBE-LVAd2), Latossolo Vermelho distrófico de Paracatu, de Sete Lagoas e de Patrocínio (PAR-LVd, SL-LVd e PAT-LVd)

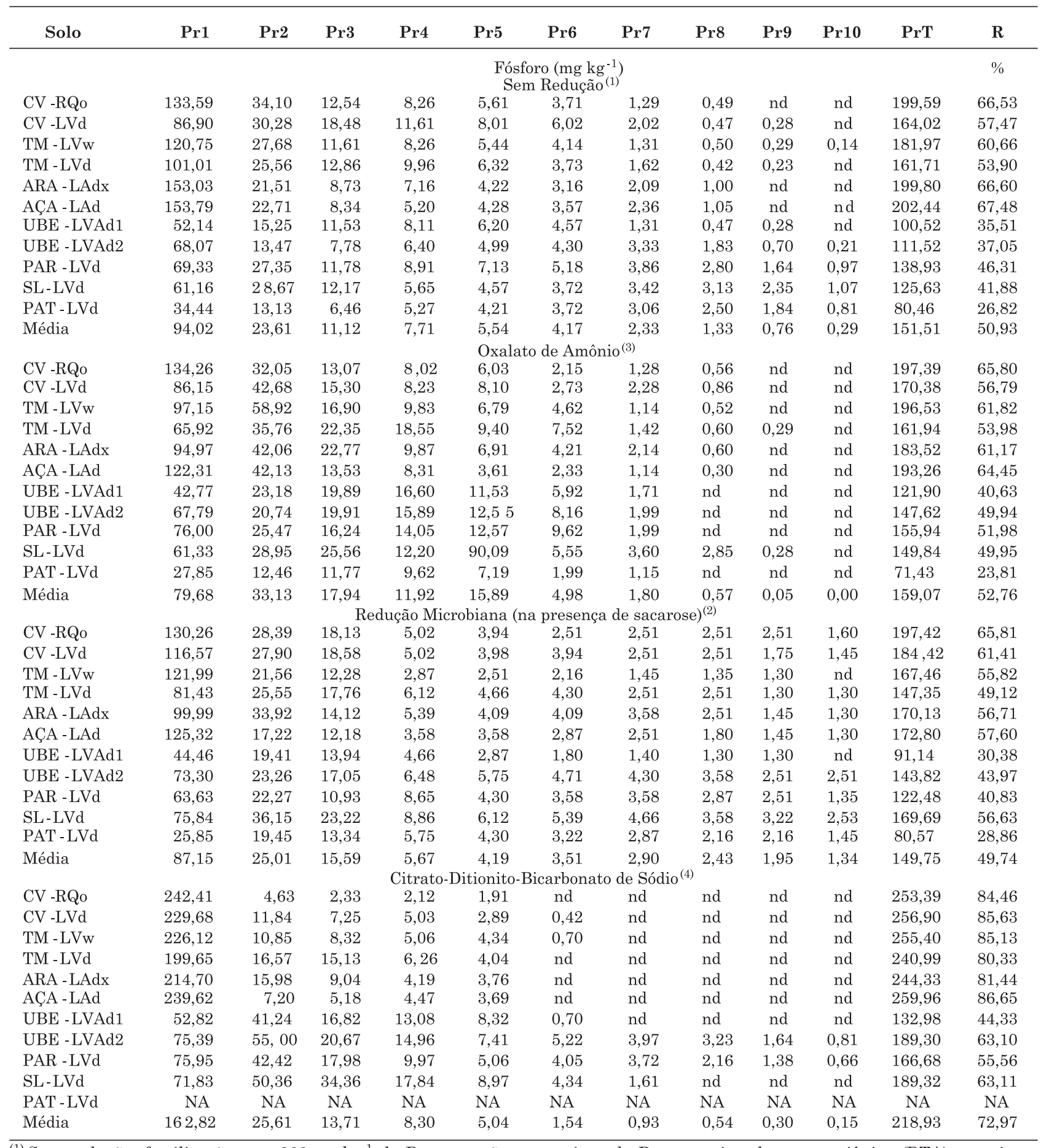

(1) Sem redução: fertilização com $300 \mathrm{mg} \mathrm{kg}^{-1}$ de $\mathrm{P}$ e extrações sucessivas de $\mathrm{P}$ com resina de troca aniônica (RTA) anterior a incubação com sacarose. Redução microbiana induzida por sacarose. ${ }^{(2)}$ e química com quatro extrações sucessivas com oxalato de amônio. ${ }^{(3)}$ ou duas extrações sucessivas com citrato-ditionito-bicarbonato de sódio. ${ }^{(4)}$ anterior à fertilização com P e extrações sucessivas de P com RTA. nd: não detectado. NA: não analisado. 
Quadro 3. Coeficientes de correlação linear simples entre o teor de P da primeira extração (Pr1), da segunda extração (Pr2), da terceira extração (Pr3) e do somatório do P das dez extrações com resina de troca aniônica (PrT) $\left(\mathrm{mg} \mathrm{kg}^{-1}\right)$, e teores de caulinita (Ct), de gibbsita (Gb) e de goethita (Gt) na fração argila $\left(\mathrm{g} \mathrm{kg}^{-1}\right)$, de amostras de solos sem redução (N) e submetidas a redução com sacarose (S), com oxalato de amônio (Ox) ou com citrato-ditionito-bicarbonato de sódio (CDB)

\begin{tabular}{|c|c|c|c|c|}
\hline & $\mathbf{C t}$ & Gb & Gt & \\
\hline & & \multicolumn{2}{|c|}{ Condições naturais } & $\operatorname{PrTN}$ \\
\hline $\operatorname{Pr} 1 N$ & $-0,147^{\mathrm{ns}}$ & $-0,759 * *$ & $-0,843^{* *}$ & $0,965^{* *}$ \\
\hline $\operatorname{Pr} 2 N$ & $-0,221^{\mathrm{ns}}$ & $-0,761^{* *}$ & $-0,326 \mathrm{~ns}$ & $0,650^{*}$ \\
\hline Pr3N & $-0,122^{n s}$ & $-0,468^{\mathrm{ns}}$ & $-0,164 \mathrm{~ns}$ & $0,244^{\mathrm{ns}}$ \\
\hline \multirow[t]{2}{*}{ PrTN } & $-0,162^{\mathrm{ns}}$ & $-0,856^{* *}$ & $-0,818^{* *}$ & --.- \\
\hline & & \multicolumn{2}{|c|}{ Sacarose } & PrTS \\
\hline $\operatorname{Pr} 1 \mathrm{~S}$ & $-0,340^{\mathrm{ns}}$ & $-0,802^{* *}$ & $-0,768^{* *}$ & $0,917 * *$ \\
\hline Pr2S & $-0,209 \mathrm{~ns}$ & $-0,367^{\mathrm{ns}}$ & $-0,028^{\mathrm{ns}}$ & $0,245^{\mathrm{ns}}$ \\
\hline Pr3S & $-0,416^{\mathrm{ns}}$ & $-0,022^{\mathrm{ns}}$ & $-0,244^{\mathrm{ns}}$ & $0,247^{\mathrm{ns}}$ \\
\hline \multirow[t]{2}{*}{ PrTS } & $-0,400^{\mathrm{ns}}$ & $-0,760 * *$ & $-0,634^{*}$ & $-\cdots$ \\
\hline & & \multicolumn{2}{|c|}{$\mathrm{Ox}$} & PrTOx \\
\hline $\operatorname{Pr} 10 \mathrm{x}$ & $-0,144^{\mathrm{ns}}$ & $-0,701^{* *}$ & $-0,700^{* *}$ & $0,909^{* *}$ \\
\hline $\operatorname{Pr} 2 \mathrm{Ox}$ & $-0,249^{\mathrm{ns}}$ & $-0,796 * *$ & $-0,710^{* *}$ & $0,813^{* *}$ \\
\hline Pr3Ox & $-0,033^{n s}$ & $-0,040^{\mathrm{ns}}$ & $-0,066^{\mathrm{ns}}$ & $0,063^{\mathrm{ns}}$ \\
\hline \multirow[t]{2}{*}{ PrTOx } & $-0,126^{\mathrm{ns}}$ & $-0,732^{* *}$ & $-0,822^{* *}$ & ---- \\
\hline & & \multicolumn{2}{|c|}{ CDB } & PrTCDB \\
\hline $\operatorname{Pr} 1 \mathrm{CDB}$ & $-0,369^{\mathrm{ns}}$ & $-0,867 * *$ & $-0,822^{* *}$ & $0,965^{* *}$ \\
\hline Pr2CDB & $0,405^{\mathrm{ns}}$ & $0,779^{*}$ & $0,503 \mathrm{~ns}$ & $-0,500^{*}$ \\
\hline Pr3CDB & $0,134^{\mathrm{ns}}$ & $-0,512^{\mathrm{ns}}$ & $0,605^{*}$ & $-0,505^{*}$ \\
\hline \multirow[t]{2}{*}{ PrTCDB } & $-0,332^{\mathrm{ns}}$ & $-0,797^{* *}$ & $-0,852^{* *}$ & -.-- \\
\hline & & PrTS & PrTOx & PrTCDB \\
\hline PrTN & & $0,827 * * * *$ & $0,926 * * *$ & $0,916^{* * *}$ \\
\hline PrTS & & -..- & $0,877 * * *$ & $0,915^{* * *}$ \\
\hline PrTOx & & & -... & $0,943^{* * *}$ \\
\hline
\end{tabular}

formas amorfas de $\mathrm{Fe}^{3+}$, pela redução microbiana e pelo $\mathrm{Ox}$, deixam a gibbsita mais ativa no sentido de adsorver e fixar mais P. Essa maior efetividade da gibbsita estaria associada ao seu arranjo espacial ou à sua maior superfície específica, visto que oxihidróxidos de $\mathrm{Al}$ com maior superfície específica e hidratação apresentam maior capacidade de adsorver e fixar $\mathrm{P}$ (Xiaofang et al., 2007). Vale salientar que a redução química com CDB gerou, neste solo (PAT-LVd), maior extração de Fe entre todos os solos estudados (dados não mostrados). Isso indica menor estabilidade das formas de Fe deste solo. Todavia, a extração de Al pelo CDB foi a menor entre todos os solos, sugerindo maior estabilidade das formas de $\mathrm{Al}$ em relação às de Fe (dados não mostrados). Assim, novamente, a gibbsita parece ser a razão para a baixa dessorção de P neste solo (PAT-LVd), visto que a desestabilização das formas de Fe, goethita em particular (Quadro 1), não alterou a capacidade extratora da resina, particularmente para $\operatorname{Pr} 1$ (Quadro 2).

$\mathrm{O}$ modelo $\mathrm{CE}=\mathrm{Co}(\mathrm{K} \mathrm{E} / \mathrm{b})^{-\mathrm{b}}$ utilizado para representar a cinética de recuperação de $\mathrm{P}$ dos solos na condição natural (sem redução) e submetidos à redução microbiana ou química com $\mathrm{Ox}$ ou com $\mathrm{CDB}$ (Quadro 2), por extrações sucessivas com resina, até sua virtual exaustão, mostrou-se adequado aos resultados obtidos (Quadro 4).
No relacionamento gráfico de CE (teor de $\mathrm{P}$ recuperado) como variável de $\mathrm{E}$ (número de extrações), fazendo-se simulações com diferentes valores de $\mathrm{Ke}$ de b da equação ajustada, observam-se que os teores de P recuperado na primeira extração variam inversamente com o valor da constante $K$, e a curvatura dessa equação é definida pela constante b (Figura 1). Essa curvatura, ou "joelho", é mais acentuada ou não, dependendo do menor ou maior valor de b. Maiores valores de $b$ indicam dessorção mais uniforme ao longo das extrações, sugerindo tendência para maior dependência entre os teores obtidos nas extrações de $\mathrm{P}$ pela resina e os valores de energia de ligação do $\mathrm{P}$ com o solo. Ao contrário, menor b indica um "joelho" mais bem definido, correspondendo à forte restrição à dessorção após a(s) primeira(s) extração(ões), podendo significar rápido e forte aumento da energia de ligação do P com o solo após a extração inicial.

Observaram-se nos solos sem redução (N) correlações positivas e significativas entre os valores da constante $\mathrm{K}$, de capacidade máxima de adsorção de $\mathrm{P}$ (CMAP), de gibbsita e, principalmente, de goethita. Isso, pelo fato de a goethita ser, como ainda será discutido neste trabalho, o maior contribuinte para o valor da CMAP dos solos estudados. Pela mesma razão, a constante $\mathrm{K}$ correlacionou-se com o teor de C orgânico (Quadro 5). Por outro lado, a 
Quadro 4. Valores das constantes b e K da equação de cinética ${ }^{(1)}$ dos teores de fósforo recuperado de amostras de solos sem redução e submetidas a redução com sacarose, com oxalato de amônio e com citratoditionito-bicarbonato de sódio, como variavel das extrações sucessivas com resina de troca aniônica em amostras dos solos; Neossolo Quartzarênico órtico e Latossolo Vermelho distrófico de Campina Verde (CV-RQo e CV-LVd), Latossolo Vermelho ácrico e Latossolo Vermelho distrófico de Três Marias (TMLVw e TM-LVd), Latossolo Amarelo distrocoeso de Aracruz (ARA-LAdx), Latossolo Amarelo distrófico de Açailândia (AÇA-LAd), Latossolo Vermelho-Amarelo distrófico 1 e 2 de Uberaba (UBE-LVAd1 e UBELVAd2), Latossolo Vermelho distrófico de Paracatu, de Sete Lagoas e de Patrocínio (PAR-LVd, SL-LVd e PAT-LVd)

\begin{tabular}{|c|c|c|c|c|c|c|}
\hline Solo & $\mathbf{b}$ & $\mathbf{K}$ & $\mathrm{R}^{2}$ & $\mathbf{b}$ & $\mathbf{K}$ & $\mathbf{R}^{2}$ \\
\hline & \multicolumn{3}{|c|}{ Sem Redução } & \multicolumn{3}{|c|}{ Redução Sacarose } \\
\hline CV-RQo & 2,4385 & 3,0134 & $0,938 * * *$ & 2,0094 & 3,1764 & $0,973^{* * *}$ \\
\hline CV-LVd & 2,4007 & 2,9992 & $0,834^{* * *}$ & 1,9012 & 3,2488 & $0,977^{* * *}$ \\
\hline TM-LVw & 2,7585 & 3,0976 & $0,909 * * *$ & 2,1435 & 3,5682 & $0,966^{* * *}$ \\
\hline TM-LVd & 2,5282 & 3,1184 & $0,880 * * *$ & 1,8257 & 3,4788 & $0,980 * * *$ \\
\hline ARA - LAdx & 2,1882 & 3,2387 & $0,978^{* * *}$ & 1,8722 & 3,3058 & $0,979^{* * *}$ \\
\hline AÇA - LAd & 2,1528 & 3,2775 & $0,971^{* * *}$ & 1,9006 & 3,6503 & $0,965^{* * *}$ \\
\hline UBE - LVAd1 & 2,1546 & 3,7895 & $0,831^{* * *}$ & 1,8130 & 4,4600 & $0,961^{* * *}$ \\
\hline UBE - LVAd2 & 1,9892 & 3,8834 & $0,847^{* * *}$ & 1,4733 & 4,0162 & $0,981 * * *$ \\
\hline PAR -LVd & 1,6733 & 3,6772 & $0,970 * * *$ & 1,9938 & 2,8953 & $0,949 * * *$ \\
\hline SL-LVd & 1,6238 & 4,0100 & $0,964^{* * *}$ & 1,5403 & 3,3835 & $0,979 * * *$ \\
\hline \multirow[t]{2}{*}{ PAT - LVd } & 1,3757 & 6,5330 & $0,942^{* * *}$ & 1,3300 & 6,3478 & $0,950 * * *$ \\
\hline & \multicolumn{3}{|c|}{ Redução Oxalato } & \multicolumn{3}{|c|}{ Redução CDB } \\
\hline CV-RQo & 2,4721 & 3,0517 & $0,957 * * *$ & 2,9706 & 4,1678 & $0,838^{*}$ \\
\hline CV-LVd & 2,3817 & 3,0767 & $0,923^{* * *}$ & 2,7235 & 3,3832 & $0,908^{* * *}$ \\
\hline TM-LVw & 2,2953 & $2,800 \quad 0$ & $0,888^{* *}$ & 2,6997 & 3,4144 & $0,900 * * *$ \\
\hline TM-LVd & 2,3260 & 2,9397 & $0,780 * *$ & 2,3111 & 3,1026 & $0,944 * *$ \\
\hline ARA - LAdx & 2,2133 & 2,9265 & $0,901^{* *}$ & 2,5288 & 3,2863 & $0,953^{* *}$ \\
\hline AÇA - LAd & 2,9849 & 3,1332 & $0,965^{* *}$ & 2,5025 & 3,6253 & $0,826^{*}$ \\
\hline UBE - LVAd1 & 1,3286 & 4,4020 & $0,741^{*}$ & 1,9423 & 3,4245 & $0,687^{*}$ \\
\hline UBE - LVAd2 & 1,8453 & 3,2544 & $0,724^{* *}$ & 1,9099 & 3,8382 & $0,925^{* * *}$ \\
\hline PAR -LVd & 1,4461 & 3,5589 & $0,817^{* *}$ & 1,9913 & 3,0817 & $0,948^{* * *}$ \\
\hline SL - LVd & 1,9405 & 3,1193 & $0,764^{* *}$ & 1,8304 & 2,8276 & $0,826^{* *}$ \\
\hline PAT-LVd & 1,3504 & 6,4203 & $0,794^{* *}$ & 1,6495 & 4,7813 & $0,769^{*}$ \\
\hline
\end{tabular}

(1) Equação: $\mathrm{CE}=\mathrm{Co}(\mathrm{K} \mathrm{E} / \mathrm{b})^{-\mathrm{b}}$, em que $\mathrm{CE}$ é o $\mathrm{P}$ recuperado nas extrações sucessivas $\left(\mathrm{mg} \mathrm{kg}^{-1}\right)$, $\mathrm{Co}^{2}$ o $\mathrm{P}$ aplicado $\left(300 \mathrm{mg} \mathrm{kg}^{-1}\right.$ de $\mathrm{P}$ no solo), E corresponde ao número de extrações, $\mathrm{K}$ é a taxa de dessorção de $\mathrm{P}$ e b é uma constante. *, ** e ***: significativo a 5,1 e $0,1 \%$, respectivamente.

constante $\mathrm{b}$, independentemente do tratamento das amostras dos solos, correlacionou-se negativamente com CMAP (Quadro 5), indicando que, nos solos com maior CMAP a dessorção do P-lábil é mais fortemente restringida após a extração inicial. Embora haja correlação negativa e significativa entre o valor da constante b e teores de gibbsita, e também de goethita (Quadro 5) em todos os tratamentos, como esperado pelo comportamento desta constante, um aspecto relativo à gibbsita chama atenção. A correlação negativa com gibbsita para o solo natural (sem redução), significativa apenas a $10 \%$, aumenta em termos numéricos e em significância à medida que o tratamento redutivo imposto ao solo torna-se mais drástico, com aumento da extração de Fe. A extração total de Fe tende a aumentar segundo a seqüência: sacarose $<\mathrm{Ox}<\mathrm{CDB}$. Como a solubilização de $\mathrm{Al}$ nessas condições tende a ser menor, dadas as características dos tratamentos, pode-se supor que a gibbsita, nessa seqüência de tratamento, fica em ambiente cada vez mais desferrificado e, portanto, mais individualizada. Nessas condições, verifica-se que o valor da constante b depende, cada vez mais, da presença de gibbsita nos solos. Pode-se, então, ter como hipótese que a dessorção do P-lábil pela gibbsita será menor nos sistemas menos goethíticos, como em Latossolos e Argissolos Amarelos. A presença de $\mathrm{Fe}^{3+}$ e de seus compostos restringem à atuação da gibbsita como adsorvente de $\mathrm{P}$ e, de modo particular, quanto à energia de adsorção deste elemento a ela.

O tratamento dos solos com CDB, o mais desferrificante deles, induz a correlação não significativa entre a constante K e CMAP, enquanto, entre a constante b e CMAP, permanece altamente significativa. Nessas condições, o valor da constante $\mathrm{K}$ resultante, como medida de quantidade de P-lábil, deixa de retratar as variações originais dos valores da CMAP dos solos, enquanto o b, como medida de qualidade (agora um sistema mais puramente gibbsítico), fica mais correlacionado (negativamente) com a CMAP. Assim, o comportamento mais qualitativo da gibbsita em termos da energia de 
adsorção de $\mathrm{P}$ nos solos, e o comportamento mais quantitativo, quanto à CMAP da goethita, são, de novo, confirmados.

A CMAP correlacionou-se positivamente com o teor de C orgânico (CO) (Quadro 6) como observado, também, em outros trabalhos (Souza et al., 2006; Ranno et al., 2007; Herlihy \& McGrath, 2007). Essa correlação positiva da CMAP com $\mathrm{CO}$ pode ser decorrente de: 1) maior adsorção de $\mathrm{P}$ pela matéria orgânica humificada via pontes metálicas (P-metal$\mathrm{CO})$, visto o caráter catiônico e a grande capacidade dos compostos orgânicos em reter metais (Souza et al., 2006); 2) solos mais argilosos, de modo geral, apresentam maior teor de CO. Assim, há efeito indireto da matéria orgânica na adsorção de P, que, nesse caso, é mais influenciada pelo teor de argila do que pela maior presença da matéria orgânica. Essa segunda possibilidade parece mais plausível dada a competição entre constituintes da matéria orgânica e o $\mathrm{P}$ adicionado pelos sítios de adsorção dos oxihidróxidos de Fe e Al (Andrade et al., 2003; Guppy et al., 2005).

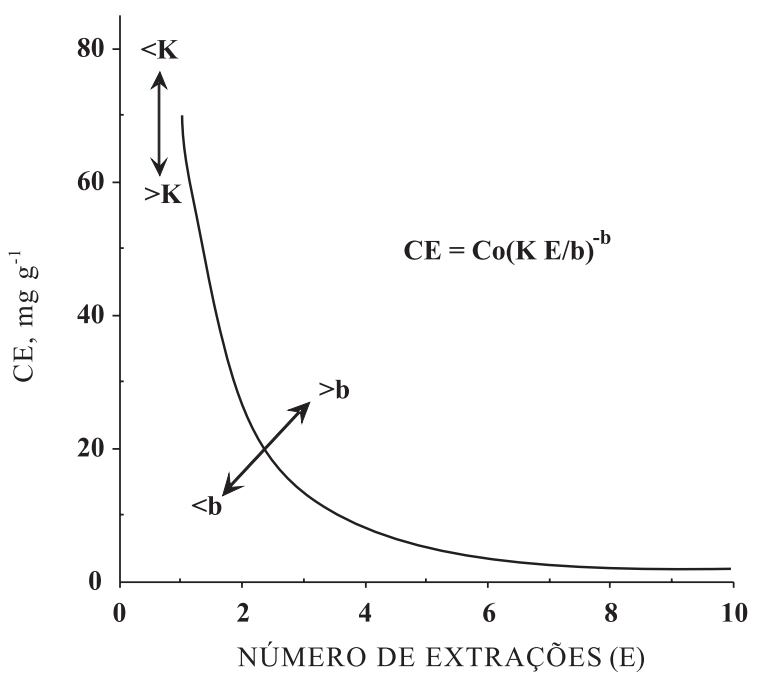

Figura 1. Forma da curva de cinética do teor de $\mathbf{P}$ recuperado pela resina de troca aniônica como variável do número de extrações sucessivas deste elemento pela resina, e sua dependência às variações das constantes $K$ e b (uma simulação). CE é o $\mathrm{P}$ recuperado pela resina de troca aniônica em $\mathrm{mg} \mathrm{kg}^{-1}$, Co é o $\mathrm{P}$ aplicado, $\mathrm{K}$ é a taxa de dessorção de $\mathrm{P}, \mathrm{E}$ é o numero de extrações sucessivas e bé uma constante.
$\mathrm{O}$ ajuste dos resultados de CMAP das amostras dos solos como variável dos constituintes mineralógicos da fração argila (Quadro 1) indica a seguinte equação:

$$
\begin{gathered}
\mathrm{CMAP}=0,17442+0,028659 * * \mathrm{~Gb}+0,069372 * * \mathrm{Gt} \\
\left(\mathrm{R}^{2}=0,945\right)
\end{gathered}
$$

sendo CMAP em mg g-1 de P no solo e Gb (gibbisita) e Gt (goethita) em percentagem desses oxihidróxidos na fração argila. Essa equação permite estimar,

Quadro 5. Coeficientes de correlação linear simples entre as constantes $K$ e b da equação cinética das concentrações de $P$ recuperado por extrações sucessivas com resina de troca aniônica e amostras de solos sem redução $(\mathrm{N})$ e submetidas a redução com sacarose (S), com oxalato de amônio $(\mathrm{Ox})$ e com citrato-ditionitobicarbonato de sódio (CDB) e o somatório do fósforo total extraído com resina $(\operatorname{PrT})\left(\mathrm{mg} \mathrm{kg}^{-1}\right)$, ferro total (FeT) (dag/kg), Capacidade Máxima de adsorção e fosfato (CMAP) $\left(\mathrm{mg} \mathrm{cm}^{-3}\right)$, carbono orgânico (CO) $\left(\mathrm{g} \mathrm{kg}^{-1}\right)$, Argila (Arg) $\left(\mathrm{g} \mathrm{kg}^{-1}\right)$, Caulinita (Ct), gibbsita (Gb) e Goethita (Gt) em percentagem da fração argila

\begin{tabular}{lllll}
\hline & \multicolumn{1}{c}{$\mathbf{N}$} & $\mathbf{S}$ & $\mathbf{O x}$ & CDB \\
\hline K vs PrT & $-0,711^{* *}$ & $-0,741^{* *}$ & $-0,907^{* * *}$ & $-0,302^{\mathrm{ns}}$ \\
K vs FeT & $0,217^{\mathrm{ns}}$ & $-0,067^{\mathrm{ns}}$ & $0,801^{* *}$ & $0,362^{\mathrm{ns}}$ \\
K vs CMAP & $0,597^{*}$ & $0,485^{\circ}$ & $0,606^{* *}$ & $-0,066^{\mathrm{ns}}$ \\
K vs CO & $0,663^{* *}$ & $0,606^{* *}$ & $0,727^{* *}$ & $0,111^{\mathrm{ns}}$ \\
K vs Arg & $0,348^{\mathrm{ns}}$ & $0,245^{\mathrm{ns}}$ & $0,482^{*}$ & $0,087^{\mathrm{ns}}$ \\
K vs Ct & $-0,215^{\mathrm{ns}}$ & $-0,158^{\mathrm{ns}}$ & $0,105^{\mathrm{ns}}$ & $-0,253^{\mathrm{ns}}$ \\
K vs Gb & $0,506^{*}$ & $0,537^{*}$ & $0,563^{*}$ & $-0,054^{\mathrm{ns}}$ \\
Kvs Gt & $0,752^{* *}$ & $0,622^{*}$ & $0,773^{* *}$ & $0,295^{\mathrm{ns}}$ \\
b vs PrT & $0,612^{*}$ & $-0,496^{\circ}$ & $0,811^{* *}$ & $0,873^{* * *}$ \\
b vs Fe & $-0,262^{\mathrm{ns}}$ & $-0,179^{\mathrm{ns}}$ & $-0,725^{* *}$ & $-0,616^{* *}$ \\
b vs CMAP & $-0,601^{*}$ & $-0,717^{* *}$ & $-0,864^{* * *}$ & $-0,906^{* * *}$ \\
b vs CO & $-0,565^{*}$ & $-0,702^{* *}$ & $-0,836^{* *}$ & $-0,888^{* * *}$ \\
b vs Arg & $-0,553^{*}$ & $-0,384^{\mathrm{ns}}$ & $-0,755^{* *}$ & $-0,748^{* *}$ \\
b vs Ct & $-0,148^{\mathrm{ns}}$ & $-0,158^{\mathrm{ns}}$ & $-0,449^{\circ}$ & $-0,319^{\mathrm{ns}}$ \\
b vs Gb & $-0,484^{\circ}$ & $-0,653^{* *}$ & $-0,787^{* *}$ & $-0,811^{* *}$ \\
b vs Gt & $-0,637^{* *}$ & $-0,689^{* *}$ & $-0,732^{* *}$ & $-0,776^{* *}$ \\
b vs K & $0,532^{*}$ & $0,696^{* *}$ & $0,672^{*}$ & $0,087^{\mathrm{ns}}$ \\
\hline
\end{tabular}

ns $,{ }^{\circ}, * * * \mathrm{e}^{* * *}$ : não significativo e significativo a $10,5,1 \mathrm{e}$ $0,1 \%$, respectivamente.

Quadro 6. Coeficientes de correlação linear simples entre teores de caulinita (Ct), gibbsita (Gb), goethita (Gt), carbono orgânico (CO) (dag/kg), argila (Arg), ferro (Fe) e alumínio (Al) (dag/kg) com capacidade máxima de adsorção de fosfatos (CMAP) $\left(\mathrm{mg} \mathrm{g}^{-1}\right)$ de amostras de solos sem redução

\begin{tabular}{cccccccc}
\hline & $\mathbf{C t}$ & $\mathbf{G b}$ & $\mathbf{G t}$ & $\mathbf{C O}$ & $\mathbf{A r g}$ & $\mathbf{F e} \mathbf{e}^{(1)}$ & $\mathbf{A l}(1)$ \\
\hline CMAP & $-0,366^{\mathrm{ns}}$ & $0,873^{* * *}$ & $0,815^{* *}$ & $0,971^{* * *}$ & $0,933^{* * *}$ & $0,556^{* *}$ & $0,973^{* * *}$ \\
\hline
\end{tabular}

(1) Totais pelo ataque nítrico-perclórico $\left(\mathrm{HNO}_{3}: \mathrm{HClO}_{4}(8: 3, \mathrm{v} / \mathrm{v})\right)$. ns, ${ }^{* *} \mathrm{e}{ }^{* * *}$ : não significativo e significativo a 1 e de $0,1 \%$, respectivamente. 
considerando apenas a gibbsita e a goethita como únicos responsáveis pela CMAP dos solos, que esses oxihidróxidos contribuem, respectivamente, com 29,2 e 70,8 \% da CMAP dos solos estudados. Essa contribuição diferencial desses oxihidróxidos com a CMAP de solos brasileiros tem sido verificada em outras pesquisas (Bahia Filho et al., 1983; Gonçalves et al., 1985).

Embora a caulinita apresente mecanismos de adsorção de $\mathrm{P}$ qualitativamente semelhantes aos dos oxihidróxidos de $\mathrm{Fe}$ e de $\mathrm{Al}$, a correlação negativa de seus teores com CMAP, neste trabalho, não se mostrou significativa (Quadro 6). Possivelmente, o capeamento da caulinita por oxihidróxidos em solos tropicais, mais intemperizados, favorece a redução da CMAP, pois a caulinita teria seus sítios de adsorção bloqueados pelos óxidos e vice-versa (Kafkafi et al., 1967). Assim, poderse-ia esperar, de fato, uma correlação negativa da caulinita "capeada" nos solos estudados com a CMAP. Correlações da CMAP com outras características do solo como teor de argila (Quadro 6), apesar de suas significativas diferenças qualitativas entre solos (Quadro 1), é fartamente citada pela literatura (Novais \& Kamprath, 1978; Rolim Neto et al., 2004; Souza et al., 2006; Herlihy \& McGrath, 2007).

Os valores de $\mathrm{P}$ remanescente (P-rem) aumentaram conforme aumentou a desferrificação das amostras dos solos, seguindo ordem crescente para os seguintes tratamentos: condição natural < redução microbiana < redução com $\mathrm{Ox}$ < redução com CDB (Quadro 7). Neste trabalho, como em outros (Alvarez V. \& Fonseca, 1990; Alvarez V. et al., 2000), a correlação entre P-rem e CMAP foi altamente significativa (Quadro 8), indicando íntima interdependência entre essas duas características dos solos. A importância prática dessa correlação é o fato de uma simples e rápida medição de P-rem substituir a bem mais trabalhosa medida da CMAP. O P-rem como medida do fator capacidade ou poder tampão de $\mathrm{P}$ no solo tem se mostrado essencial à interpretação de resultados do $\mathrm{P}$ disponível do solo por diferentes extratores químicos (Muniz et al., 1985; Novais \& Smyth, 1999).

Para o tratamento sem redução, as correlações entre P-rem (P-remN) e características do solo ligadas à CMAP apresentaram-se na quase totalidade significativas, sendo a caulinita a exceção (Quadro 8). Todavia, o comportamento do P-rem nos solos submetidos à redução microbiana (sacarose) ou química (Ox ou $\mathrm{CDB}$ ) é fora do esperado para grupo de solos mais oxídicos (UBE-LVAd1, UBE-LVAd2, PAR-LVd, SL-LVd e PAT-LVd). Enquanto no primeiro grupo, solos menos oxídicos (CV-RQo, CV-LVd, TMLVw, TM-LVd, ARA-LAdx e AÇA-LAd), a redução microbiana apresentou pequeno efeito sobre o P-rem, em relação ao tratamento sem redução, enquanto no grupo dos solos mais oxídicos o efeito da redução microbiana foi grande (Quadro 7). Como os valores do P-lábil dessorvido do solo sem redução ou do solo submetido à redução microbiana foram semelhantes (Quadro 2), verifica-se que o efeito da redução
Quadro 7. Valores de fósforo remanescente de amostras dos solos sem redução (N) e submetidas a redução com sacarose (S), com oxalato de amônio $(\mathrm{Ox})$ e com citrato-ditionitobicarbonato de sódio (CDB) em amostras dos solos; Neossolo Quartzarênico órtico e Latossolo Vermelho distrófico de Campina Verde (CV-RQo e CV-LVd), Latossolo Vermelho ácrico e Latossolo Vermelho distrófico de Três Marias (TM-LVw e TM-LVd), Latossolo Amarelo distrocoeso de Aracruz (ARA-LAdx), Latossolo Amarelo distrófico de Açailândia (AÇA-LAd), Latossolo Vermelho-Amarelo distrófico 1 e 2 de Uberaba (UBE-LVAd1 e UBE-LVAd2), Latossolo Vermelho distrófico de Paracatu, de Sete Lagoas e de Patrocínio (PAR-LVd, SL-LVd e PAT-LVd)

\begin{tabular}{lrrrr}
\hline \multicolumn{1}{c}{ Solo } & N & S & Ox & CDB \\
\cline { 3 - 5 } & & \multicolumn{4}{c}{ mg L $^{-1}$} & \\
\cline { 2 - 5 } CV - RQo & 37,1 & 49,8 & 57,9 & 60,0 \\
CV - LVd & 21,1 & 41,0 & 54,4 & 59,4 \\
TM - LVw & 38,1 & 52,7 & 56,7 & 60,0 \\
TM-LVd & 29,9 & 45,8 & 49,8 & 58,4 \\
ARA - LAdx & 29,9 & 45,8 & 55,8 & 60,0 \\
AÇA - LAd & 46,1 & 51,2 & 60,0 & 60,0 \\
UBE - LVAd1 & 3,4 & 33,0 & 24,2 & 47,0 \\
UBE - LVAd2 & 4,8 & 33,9 & 26,4 & 44,5 \\
PAR -LVd & 4,6 & 34,9 & 18,9 & 47,0 \\
SL-LVd & 3,2 & 31,2 & 39,9 & 35,8 \\
PAT - LVd & 1,8 & 32,1 & 18,9 & 27,2 \\
Média & 20,0 & 41,0 & 42,1 & 50,8 \\
\hline
\end{tabular}

microbiana aumentando o P-rem (ou diminuindo a CMAP) não interferiu sobre a dessorção de $\mathrm{P}$ desses solos, avaliada pelas extrações sucessivas com resina (PrT). Nos solos mais oxídicos, o efeito da redução microbiana gerou forte queda da CMAP original (em torno de 10 vezes, em média) sem, contudo, alterar a dessorção do $\mathrm{P}$ anteriormente adsorvido. Isso contrariou a expectativa inicial de maior dessorção de P nos solos com redução microbiana e química, como sugerido em outros estudos em ambientes redutivos (Song et al., 2006; Bostic \& White, 2007; Peng et al., 2007). Possivelmente, de modo particular nos solos mais oxídicos, produtos da atividade microbiana ativada pela sacarose, como ácidos orgânicos produzidos por um provável processo fermentativo ocorrido, bloquearam os óxidos e suas cargas. Assim, há menor adsorção do $\mathrm{P}$ aplicado, sem, contudo, alterar a dessorção daquele anteriormente adsorvido.

É interessante observar que as mesmas características dos solos que se correlacionam com o P-rem, sem redução (P-remN), correlacionam-se, também, com o P-rem obtido para os solos depois de submetidos à redução microbiana (P-remS), com $\mathrm{Ox}$ (P-remOx) ou com CDB (P-remCDB) (Quadro 8). Semelhantemente, o P-remN correlacionou-se, significativamente, com o P-rem encontrado nos 
Quadro 8. Coeficientes de correlação linear simples entre teores de caulinita (Ct), de gibbsita (Gb), de goethita $(\mathrm{Gt})$ em percentagem, capacidade máxima de adsorção de fosfato (CMAP), argila (Arg), carbono orgânico (CO), e P remanescente (P-rem) de amostras dos solos sem redução (N) e submetidas a redução com sacarose $(\mathrm{S})$, com oxalato de amônio $(\mathrm{Ox})$ e com citrato-ditionitobicarbonato de sódio (CDB)

\begin{tabular}{lcccc}
\hline & P-remN & P-remS & P-remOx & P-remCDB \\
\hline Ct & $-0,362^{\text {ns }}$ & $-0,350^{\text {ns }}$ & $-0,488^{\text {ns }}$ & $-0,092^{\mathrm{ns}}$ \\
Gb & $-0,805^{* *}$ & $-0,773^{* *}$ & $-0,910^{* * *}$ & $-0,708^{* *}$ \\
Gt & $-0,804^{* *}$ & $-0,824^{* *}$ & $-0,730^{* *}$ & $-0,935^{* * *}$ \\
CMAP & $-0,963^{* * *}$ & $-0,956^{* * *}$ & $-0,938^{* * *}$ & $-0,900^{* * *}$ \\
Arg & $-0,913^{* * *}$ & $-0,924^{* * *}$ & $-0,852^{* *}$ & $-0,788^{* *}$ \\
CO & $-0,905^{* * *}$ & $-0,905^{* * *}$ & $-0,924^{* * *}$ & $-0,923^{* * *}$ \\
P-remN & ---- & $0,986^{* * *}$ & $0,907^{* * *}$ & $0,844^{* *}$ \\
P-remS & & $-\cdots$ & $0,872^{* *}$ & $0,857^{* *}$ \\
P-remOx & & & $-\cdots$ & $0,812^{* *}$ \\
\hline
\end{tabular}

ns, $* *$ e ***: não significativo e significativo a 1 e de $0,1 \%$, respectivamente.

tratamentos com redução. Essa constatação era inesperada visto que os tratamentos, como o CDB em particular, atuam diferentemente entre os solos, dadas suas características mais goethíticas ou gibbsíticas. Quando se analisam os dados de P-remN e P-remS (Quadro 7), verifica-se que eles têm duas populações bem distintas, correspondentes aos dois grupos de solos, já bem definidos e discutidos anteriormente.

Pode-se conjecturar que a redução que ocorre em solos hidromórficos, geralmente enriquecidos com Corgânico, é bem mais efetiva quanto a futuras fertilizações fosfatadas do que solos bem drenados, e que poderiam ser alagados por períodos prolongados, com a expectativa de liberação de formas fixadas de $\mathrm{P}$ anteriormente adicionadas. Portanto, o efeito do Corgânico (sacarose, neste estudo) é, aparentemente, muito mais que uma simples condição para diminuição do Eh como consequência do aumento da atividade microbiana do sistema.

\section{CONCLUSÕES}

1. O desenvolvimento de formas não-lábeis de $\mathrm{P}$ a partir da fertilização fosfatada é dependente principalmente da goethita e da gibbsita.

2. Comparada à goethita, a gibbsita apresenta maiores restrições à dessorção de $\mathrm{P}$.

3. A condição de redução (menor potencial redox) dos solos, microbiana (solução de sacarose) ou química pelas extrações com oxalato de amônio, não favorece a reversibilidade de formas não-lábeis de $\mathrm{P}$ previamente formadas.
4. A redução das amostras de solo com sacarose promove expressiva elevação nos valores de Premanescente (reduz capacidade máxima de adsorção de $\mathrm{P}$ ) apenas nos solos mais oxídicos, sem alterar a taxa de dessorção de $\mathrm{P}$ previamente aplicado aos solos.

\section{LITERATURA CITADA}

AGBENIN, J.O. Extractable iron and aluminum effects on phosphorus sorption in a Savanna alfisol. Soil Sci. Soc. Am. J., 67:589-595, 2003.

ALMEIDA, J.A.; TORRENT, J. \& BARRÓN, V. Cor de solo, formas de fósforo e adsorção de fosfatos em Latossolos desenvolvidos de basalto do extremo-sul do Brasil. R. Bras. Ci. Solo, 27:985-1002, 2003.

ALVAREZ V., V.H. \& FONSECA. D.M. Definição de doses para determinação da capacidade máxima de adsorção de fosfatos e para ensaios em casa de vegetação. R. Bras. Ci. Solo, 14:49-55, 1990.

ALVAREZ V., V.H.; NOVAIS, R.F.; DIAS, L.E. \& OLIVEIRA, J.A. Determinação e uso do fósforo remanescente. B. Inf. SBCS, 25:27-32, 2000.

ANDRADE, F.V.; MENDONÇA, E.S.; ALVAREZ V., V.H. \& NOVAIS, R.F. Adição de ácidos orgânicos e húmicos em Latossolos e adsorção de fosfato. R. Bras. Ci. Solo, 27:10031011, 2003.

BAHIA FILHO, A.F.C.; BRAGA, J.M.; RESENDE, M. \& RIBEIRO, A.C. Relação entre adsorção de fósforo e componentes mineralógicos da fração argila de Latossolos do planalto central. R. Bras. Ci. Solo, 7:221-226, 1983.

BARROW, N.J. Effect of previous additions of phosphate in adsorption by soil. Soil Sci., 118:82-89, 1974.

BARROW, N.J. Reactions of anions and cations with variablecharge soil. Adv. Agron., 38:183-230, 1985.

BOSTIC, E.M. \& WHITE, J.R. Soil phosphorus and vegetation influence on wetland phosphorus release after simulated drought. Soil Sci. Soc. Am. J., 71:238-244, 2007.

CAMPELLO, M.R.; NOVAIS, R.F.; FERNÁDEZ R., I.E.; FONTES, M.P.F. \& BARROS, N.F. Avaliação da reversibilidade de fósforo não-lábil para lábil em solos com diferentes características. R. Bras. Ci. Solo, 18:157$165,1994$.

CHACON, N.; SILVER, W.L.; DUBINSKY, E.A. \& CUSACK, D.F. Iron and soil phosphorus solubilization in humid tropical forests soils: The roles of labile carbon polls and an electron shuttle compound. Biogeochemistry,78:67$84,2006$.

DEFELIPO, B.V. \& RIBEIRO, A.C. Análise química do solo. 2.ed. Viçosa, MG, Universidade Federal de Viçosa, 1997. $26 \mathrm{p}$.

EMPRESA BRASILEIRA DE PESQUISA AGROPECUÁRIA EMBRAPA. Serviço Nacional de Levantamento e Conservação de Solos. Manual de métodos e análises de solo. Rio de Janeiro, 1997. 
GONÇALVES, J.L.M.; FIRME, D.J.; NOVAIS, R.F. \& RIBEIRO, A.C. Cinética de adsorção de fósforo em solos de cerrado. R. Bras. Ci. Solo, 9:107-111, 1985.

GONÇALVES, J.L.M.; NOVAIS, R.F.; BARROS, N.F.; NEVES, J.C.L. \& RIBEIRO. A.C. Cinética da transformação de fósforo-lábil em não-lábil, em solos de cerrado. R. Bras. Ci. Solo, 13:13-24, 1989 .

GUPPY, C.N.; MENZIES, N.W.; MOODY, P.W. \& BLAMEY, F.P.C. Competitive sorption reactions between phosphorus and organic matter in soil: A review. Aust. J. Soil. Res., 43:189-202, 2005.

HERLIHY, M. \& McGRATH, D. Phosphorus fractions and adsorption characteristics in grassland soils of soil phosphorus status. Nutr. Cycl. Agroecosyst., 77:15-27, 2007.

HUTCHISON, K. J. \& HESTERBERG, D. Dissolution of phosphate in a phosphorus-enriched Ultisol as affected by microbial reduction. J. Environ. Qual., 33:1793-1802, 2004.

KAFKAFI, V.; POSNER, A.M. \& QUIRK, J.P. The desorption of phosphate from kaolinite. Soil Sci. Am. Proc., 31:348$351,1967$.

McLAUGHLIN, J.R.; RUDEN, J.C. \& SYERS, J.K. Sorption of inorganic phosphate by iron and aluminum-containing components. J. Soil Sci., 32:365-377, 1981.

MUNIZ, A.S.; NOVAIS, R.F.; BARROS, N.F. \& NEVES, J.C.L. Nível crítico de fósforo na parte aérea da soja como variável do fator capacidade de fósforo do solo. R. Bras. Ci. Solo, 9:237-243, 1985.

MURPHY, J. \& RILEY, J.P. A modified single solution method for determination of phosphate in natural waters. Anal. Chim. Acta, 27:31-36, 1962.

NOVAIS, R.F. \& KAMPRATH, E.J. Phosphorus supplying capacities of previously heavily fertilized soils. Soil Sci. Soc. Am. J., 42:931-935, 1978.

NOVAIS, R.F. \& SMYTH, T.J. Fósforo em solo e planta em condições tropicais. Viçosa, MG, Universidade Federal de Viçosa, 1999. 399p.

NOVAIS, R.F.; SMYTH, T.J. \& NUNES, F.N. Fósforo In: NOVAIS, R.F.; ALVAREZ V., V.H.; BARROS, N.F.; FONTES, R.L.F.; CANTARUTTI, R.B. \& NEVES, J.C.L., eds. Fertilidade do solo. Viçosa, MG, Sociedade Brasileira de Ciência do Solo, 2007. p.471-550.

OLSEN, S.R. \& WATANABE, F.S. A method to determine a phosphorus adsorption maximum of soils as measured by the Langmuir isoterm. Soil Sci. Am. Proc., 21:144-149, 1957.
PARFITT, R.L. Anion adsorption by soil material. Adv. Agron., 30:1-50, 1978

PARFITT, R.L. Phosphate reactions with natural allophane, ferrihydrita and goethita. J. Soil Sci., 40:359-369, 1989.

PENG, J.F.; WANG, B.Z.; SONG, Y.H.; YUAN, P. \& LIU, Z. Adsorption and release of phosphorus in the surface sediment of wastewater stabilization pond. Ecol. Eng., 31:92-97, 2007.

RAIJ, B.van \& QUAGGIO, J.A. Métodos de análise de solos para fins de fertilidade. Campinas, Instituto Agronômico de Campinas, 1983. 31p.

RANNO, S.K.; SILVA, L.S.; GATIBONI, L.C. \& RHODEN, A.C. Capacidade de adsorção de fósforo em solos de várzea do estado do Rio Grande do Sul. R. Bras. Ci. Solo, 31:21-28, 2007.

RESENDE, M.; BAHIA FILHO, A.F.C. \& BRAGA, J.M Mineralogia de latossolos estimada por alocação a partir do teor total de óxidos do ataque sulfúrico. R. Bras. Ci. Solo, 11:17-23, 1987.

ROLIM NETO, F.C.; SCHAEFER, C.E.G.R.; COSTA, L.M.; CORRÊA, M.M.; FERNANDES FILHO, E.I. \& IBRAIMO, M.M. Adosorção de fósforo, superfície específica e atributos mineralógicos em solos desenvolvidos de rochas vulcânicas do Alto do Paranaíba (MG). R. Bras. Ci. Solo, 28:953-964, 2004

SCALENGUE, R.; EDWARDS, A.C.; AJMONE MARSAN, F. \& BARBERIS, E. The effect of reducing conditions on the solubility of phosphorus in a diverse range of European Agricultural Soils. Eur. J. Soil Sci., 53:439-447, 2002.

SONG, K.Y.; ZOH, K.D. \& KANG, H. Release of phosphate in a wetland by changes in hydrological regime. Sci. Total Environ., 380:13-18, 2007.

SOUZA, R.F.; FAQUIN, V.; TORRES, P.R.F. \& BALIZA, D.P. Calagem e adubação orgânica: Influnência na adsorção de fósforo em solos. R. Bras. Ci. Solo, 30:975-983, 2006.

SRINIVASARAO, C.; SINGH, R.N.; GANESHAMURTHY, A.N.; GHANSHAM, S. \& MASOOD, A. Fixation and recovery of added phosphorus and potassium in different soil types of pulse-growing regions of India. Comm. Soil Sci. Plant. Anal., 38:449-460, 2007.

XIAOFANG, Y.; DONGSHENG, W.; ZHONGXI, S. \& HONGXIAO, T. Adsorption of phosphate at the aluminum (hydr)oxides-water interface: Role of the surface acidbase properties. Colloid Surf. A, 297:84-90, 2007.

YUAN, G. \& LAVKULICH, L.M. Phosphorus sorption in relation to extractable iron and aluminum in Spodosols. Soil. Sci. Soc. Am. J., 58:343-346, 1994. 